\title{
Expression of CD11b and CD18 on polymorphonuclear neutrophils stimulated with interleukin-2
}

\author{
BAHAA K.A. ABDEL-SALAM, HOSSAM EBAID
}

King Saud University, Riyadh, Saudi Arabia

\begin{abstract}
Background: Interleukin-2 (IL-2) is a lymphocyte-activating and growth-promoting factor, and has been widely studied on T-cells and NK-cells. However, the interaction of polymorphonuclear neutrophils (PMNs) with IL-2 is poorly studied and thus, this study aimed at defining IL-2 participation in the expression of CD11b and CD18 on PMNs.

Material and methods: PMNs were isolated from heparinized whole blood of healthy donors. Purified cells were incubated with $I L-2(10 \mathrm{ng} / \mathrm{ml})$ for 24 hours at $37^{\circ} \mathrm{C}$ in a humidified incubator with $5 \% \mathrm{CO}_{2}$. After 24 hours' incubation, surface molecules (CD11b and CD18) were measured by flow cytometry.

Results: Interestingly, the antibodies of IL-2R $\beta$ chain (CD122-FITC) were found in all observed cells. The induction of CD11 b mean fluorescence intensity (MFI) in highly purified PMNs stimulated with IL-2 was clearly increased recording $43 \%$ in comparison to the freshly isolated PMNs and the un-stimulated PMNs which were found to be $23 \%$ and $28 \%$ of CD11b, respectively. Furthermore, flow cytometry analysis demonstrated that the highly purified PMNs exposed to IL-2 showed an increase in CD18 MFI, recording 47\% with respect to that of the freshly isolated PMNs and PMNs cultured with the medium alone which showed a small amount of $38 \%$ and $27 \%$, respectively.

Conclusions: Results demonstrated that $C D 11 \mathrm{~b}$ and $C D 18$ had been acquired on the surface of the IL-2-in vitro-activated PMNs. These findings indicated that IL-2 may play a crucial role in PMNs migration.
\end{abstract}

Key words: IL-2, IL-2Rß chain, PMNs, adhesion molecules (CD11b, CD18).

(Centr Eur J Immunol 2014; 39 (2): 209-215)

\section{Introduction}

Leukocyte-endothelial cell interactions in tissues are mediated by adhesion molecules expressed on the surface of leukocytes and endothelial cells [1]. Immunoglobulin superfamily molecules such as intercellular adhesion molecule-1 (ICAM-1) are expressed on endothelial cells and bind to $\beta 2$-integrins expressed on leukocytes. Integrins are noncovalently linked heterodimers of $\alpha$ and $\beta$ subunits that are expressed on the cell surface $[2,3]$. Although originally identified as adhesion molecules, integrins are now known to mediate a wide variety of signaling functions, and consequently, integrins influence many biologic systems. They are involved in hematopoiesis, hemostasis, immune regulation, and the inflammatory response [4]. Integrins are critically involved in the trafficking of leukocytes from the bloodstream to extravascular tissue at sites of active inflammation as well as during routine immune surveillance. Studies have established a sequence of adhesive events involved in leukocyte emigration. Some leukocytes stick firmly, migrate along the endothelial surface, diapedese between endothelial junctions, and then migrate through a subendothelial matrix using endothelial receptors in an adhesion cascade [5].

The $\beta 2$ integrin (CD18) expressed on leukocytes can pair with several $\alpha$ integrin (CD11) subunits, and each $\alpha \beta$ pairing can bind a variety of ligands, including the counter receptors ICAM-1, -2, and -3; fibrinogen; the complement fragment $\mathrm{iC} 3 \mathrm{~b}$; and polysaccharides [6].

Chronic inflammation in lung diseases contributes to lung tissue destruction leading to the formation of chemotactic collagen. It was demonstrated that CD11b/CD18 (Mac-1) was responsible for adhesion of neutrophils to fibrinogen [7]. In addition, CD11b-integrin mediated atrial PMN infiltration to the formation of fibrosis [8].

Acute emigration of neutrophils requires CD11/CD18 complexes under most circumstances [5]. Antibodies

Correspondence: Hossam Ebaid, Department of Biology, Faculty of Science, Shaqra University, Shaqra, Saudi Arabia, e-mail: manar_muhamad@yahoo.com 
against CD11/CD18 inhibit neutrophil emigration during acute inflammation in animals [9], despite the crucial role of neutrophil in inflammations $[10,11]$. Previous studies outlined the importance of CD18 for granulocyte locomotion in vivo and in vitro [12], at least for two-dimensional movement and possibly egress from the vascular space [13]. In resting neutrophils, it has been shown that $\beta 2$-integrin exists in association with talin, that this association is disrupted when talin is cleaved by calpain after neutrophil stimulation, and that subsequently $\beta 2$-integrin is found to associate with $\beta$-actinin [14].

Polymorphonuclear neutrophils (PMNs) have a very short half-life in the circulation because they constitutively undergo apoptosis [15]. Under certain conditions, PMNs play an important role in the effector arm of host immune defense through the clearance of immune complexes, the phagocytosis of opsonized particles, and the release of inflammatory mediators [16-18]. During recent years the image of PMNs has changed considerably and traditionally considered to be the first-line defense against bacterial infection. It became increasingly clear that PMNs also participate in chronic inflammatory disease and regulation of the immune response when appropriately activated [19].

Monocytes have been reported to express IL-2R $\beta$ and to be activated by IL-2 for tumoricidal activity [20]. Thus far, PMNs have not been studied for their interaction with IL-2. The direct effect of IL-2 on PMNs, especially the mechanisms involved in the activation of PMNs, is unknown, although the ability of other immune cells to respond to IL-2 is well studied. Preliminary studies have shown that PMNs have the capacity to respond to IL-2 with an increased antifungal activity [21]. More importantly, it has been identified that PMNs express surface receptors for IL-2, but only IL-2R $\beta$ and not IL-2R $\alpha$ is present [22]. Thus, PMNs stimulated with IL-2 and the subsequent expression of CD11b and CD18 that play an important role in adhesion and migration are investigated in this study.

\section{Material and methods}

\section{Experimental materials and antibodies}

All chemicals and materials employed in this study were of analytical grade. All antibodies applied in this study [anti-mouse IgG-FITC, anti-CD122-FITC (Serotec; Oxford, UK), anti-CD66-FITC (Immunotech, Marseille, France), anti-CD11b-FITC, anti-CD18-FITC (Serotec; Oxford, UK)] are a kind gift from Prof. Dr. G. M. Haensch, Immunology Institute, Heidelberg, Germany.

\section{Isolation of PMNs from blood samples}

Blood was taken by venous puncture using $7.5 \mathrm{ml}$ heparin-coated tubes (Sarstedt; Nümbrecht, Germany) and was analyzed within 2 hours. Cells were isolated by PolymorphPrep ${ }^{\circledR}$ [23] (Nycomed; Oslo, Norway). PMNs were further purified by adsorption to CD15 beads (Miltenyi Biotec; Bergisch Gladbach, Germany) by magnetic cell separation using the devices supplied by Miltenyi Biotec (Bergisch Gladbach, Germany).

\section{Cultivation of highly purified PMNs}

Highly purified PMNs $\left(1 \times 10^{6} / \mathrm{ml}\right)$ were cultivated in AIM V (Gibco BRL; Paisley, Scotland) with $2.5 \%$ autologous normal human serum, NHS (inactivated at $56^{\circ} \mathrm{C}$ for $30 \mathrm{~min}$ ). Cells were incubated at $37^{\circ} \mathrm{C}$ and $5 \% \mathrm{CO}_{2}$ for the times indicated. Highly purified PMNs were placed into a 24-well plate (Nunc ${ }^{\mathrm{Tm}}$; Roskilde, Denmark), $2 \mathrm{ml} /$ well, and incubated in the presence or absence of $10 \mathrm{ng} / \mathrm{ml} \mathrm{IL-2}$ (Sigma; St Louis, MO, USA) for about 24 hours at $37^{\circ} \mathrm{C}$ with $5 \% \mathrm{CO}_{2}$.

\section{Intracellular FACS-staining of PMNs}

For intracellular FACS-staining of PMNs in whole blood, the intracellular proteins were blocked by adding $10 \mu \mathrm{g}$ of Brefeldin A / $\mathrm{ml}$ to whole blood for about 4 hours at $37^{\circ} \mathrm{C} / 5 \% \mathrm{CO}_{2}$. The permeability of the cell membrane was increased by adding $500 \mu \mathrm{l} 1 \times$ FACS permeabilizing solution. Cells were washed with FACS buffer + Saponin $0.2 \%$ and stained with $2 \mathrm{mg}$ of anti-CD122-FITC. Anti-mouse IgG-FITC and anti-CD66-FITC were used as a positive and negative control, respectively. FITC conjugated antibodies mixed well and incubated as mentioned above. Cells were washed three times with 2 ml FACS buffer + Saponin $0.2 \%$, fixed by $300 \mu \mathrm{l}$ of $1 \%$ PFA and analyzed by FACSCalibur and CellQuest software (Becton-Dickinson, Heidelberg, Germany). Results are expressed as a percentage of positive cells Mean Fluorescence Intensity (MFI) in the respective gate.

\section{Immunocytochemistry and confocal laser microscopy}

For immunocytochemistry, freshly isolated PMNs by two hypotonic/hypertonic lysis steps with $0.2 \% / 1.6 \%$ saline were fixed on slides $\left(2 \times 10^{5}\right.$ cells/slide) by a cytospin 4 centrifuge (Shandon; Frankfurt, Germany) and ice-cold methanol. Cells were incubated with 5\% goat serum (Sigma; Saint Louis, MO, USA) in PBS followed by $2 \mathrm{mg}$ of anti-CD122-FITC. Anti-mouse IgG-FITC and antiCD66-FITC were used as a positive and negative control, respectively. The slides were examined by confocal laser microscopy (Leica, Bensheim, Germany) using Windows TC as software.

For integrins detection, freshly highly purified PMNs were stained with $2 \mathrm{mg}$ of anti-CD11b-FITC and CD18FITC. Anti-mouse IgG-FITC and anti-CD66-FITC were used as a positive and negative control, respectively. Cells were analyzed as mentioned by IL-2R $\beta$, but results are ex- 
pressed as a percentage of positive cells mean fluorescence intensity (MFI).

\section{Statistical analysis}

The statistical analysis was performed using the MINITAB software (MINITAB, State College, PA, Version 13.1, 2002). The data from the experiments were tested for normality using the Anderson Darling test, and for variance homogeneity prior to any further statistical analysis. The data were normally distributed with homogeneous variances. Thus, the one-way ANOVA statistical measure was used to determine the overall effect of each treatment. This measure was supplemented by individual comparison between the different treatments using Tukey's method for pairwise comparisons. The results were expressed as arithmetic mean $(\mathrm{M}) \pm$ standard deviation $(\mathrm{SD})$. Only statistically significant differences with $p<0.05$ were found between the treatment group and the control, and between the treatment group and the diabetic group considered.

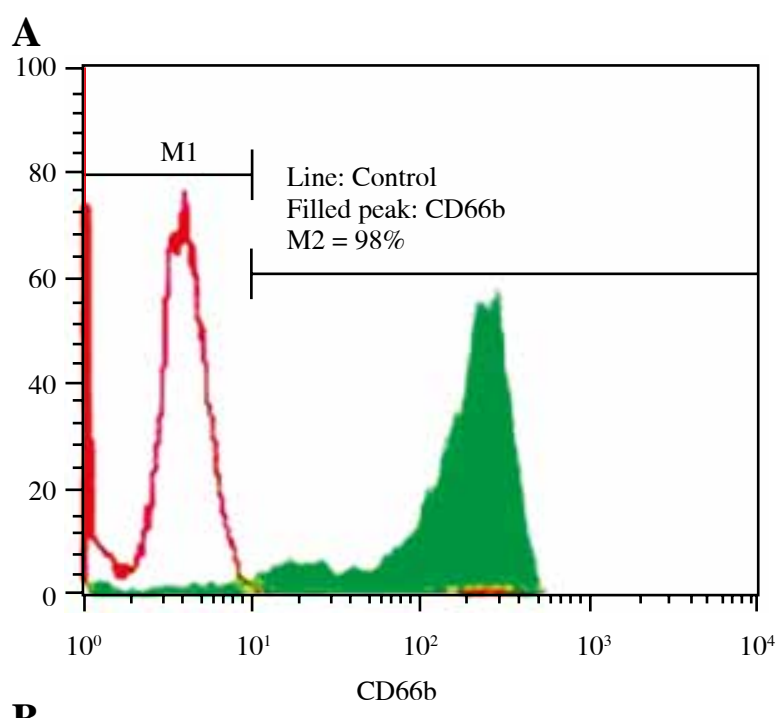

B

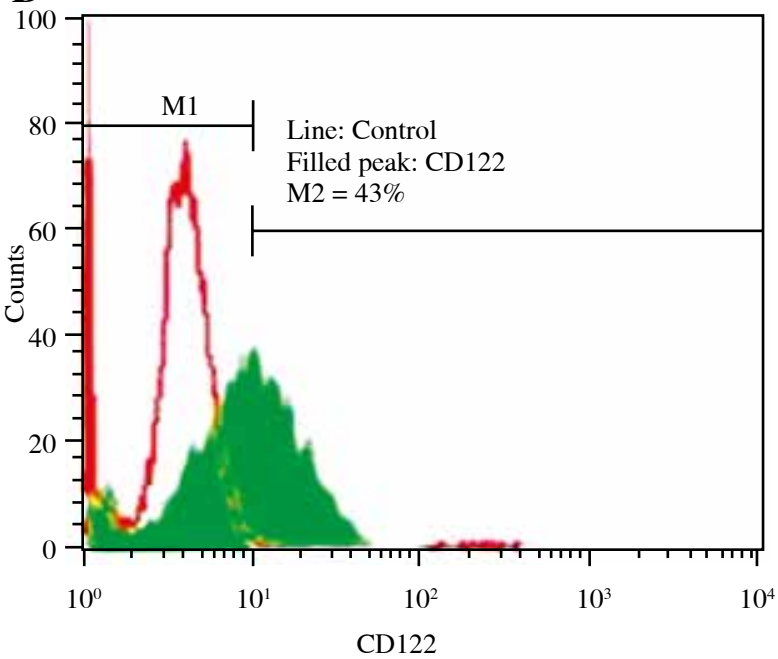

\section{Results}

\section{Intracellular detection of the IL-2R $\beta$ chain in whole blood}

At the beginning of this experiment, it was important to address whether PMNs have receptors for IL-2 or not. To detect IL-2R $\beta$ chain, the intracellular protein-release was prevented using $10 \mu \mathrm{g} \mathrm{BFA} / \mathrm{ml}$ for 4 hours at $37^{\circ} \mathrm{C} / 5 \% \mathrm{CO}_{2}$. Fig. 1A showed that PMNs recorded 98\% of CD66b-FITC (positive marker of PMNs). Interestingly, the antibodies of IL-2R $\beta$ chain (CD122-FITC) recorded 43\% (Fig. 1B).

\section{Visualization of the IL-2R $\beta$ chain by immunocytochemistry}

Further, the isolated PMNs by a hypotonic solution were examined by confocal laser microscopy. Mouse IgG-FITC was used as a negative control (Fig. 2A), while CD66b-FITC was used as a positive control (Fig. 2B).

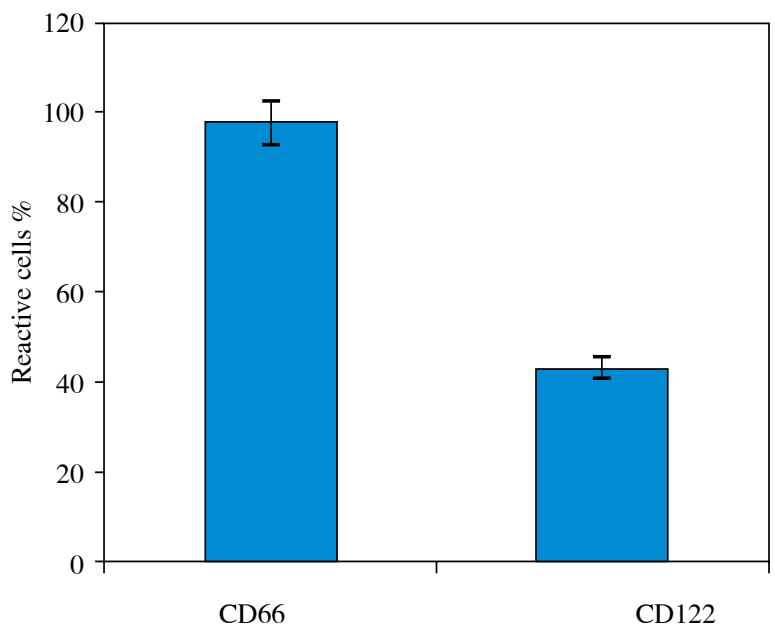

*shows the significance of IL-2 stimulated PMNs in comparison to the freshly isolated PMNs and PMNs cultured with medium alone for 24 hours

Fig. 1. Intracellular detection of IL-2R $\beta$ chain (filled peaks; the line is the negative control): A) The positive marker of PMNs (CD66b-FITC), B) IL-2R $\beta$ chain (CD122-FITC) on the right. Values shown are mean values $\pm \mathrm{SD}$ 

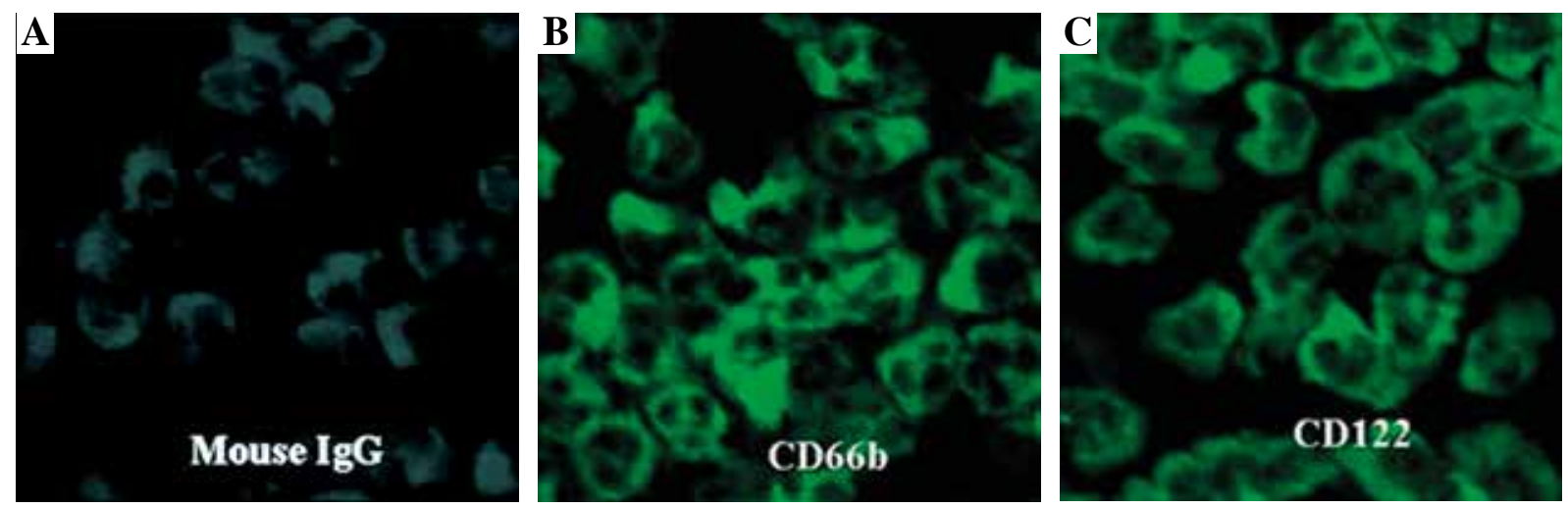

Fig. 2. Detection of IL-2Rb chain on PMNs: The negative and positive controls were in panels $\mathbf{A}$ and $\mathbf{B}$, respectively, while panel $\mathbf{C}$ showed the CD122 (magnification 400x)

The IL-2Rb chain (CD122-FITC) was found in all observed cells (Fig. 2C) in all trials.

\section{Expression of CD11b on PMNs stimulated with IL-2}

Thereafter, we further tried to address if IL-2 stimulation can express CD11b. To test effects of IL-2 on CD11b expression on PMN cells, we evaluated the fluorescence intensity. The expression of CD11b on the freshly isolated PMNs and PMNs cultured with medium alone for 24 hours are shown in Fig. 3A and 3B, respectively. The induction of CD11b mean fluorescence intensity (MFI) in highly purified PMNs 24 hour-cultured with IL-2 was significantly increased recording $43 \%$ (Fig. 3C) in comparison to the freshly isolated PMNs which showed 23\% of the CD11b expression and the PMNs cultured with medium alone for 24 hours which had also a small amount (28\%) of CD11b.

\section{Expression of CD18 on PMNs stimulated with IL-2}

We next tested the expression of CD18 on PMNs. The expression of CD18 on the freshly isolated PMNs and PMNs cultured with medium alone for 24 hours are shown in Figs. 4A and 4B, respectively. The highly purified PMNs exposed to IL-2 for 24 hours and tested by flow cytometry, showed an increase in CD18 MFI recording 47\% (Fig. 4C) with respect to the MFI of freshly isolated PMNs and PMNs cultured with medium alone for the same time which showed a small amount $(38 \%$ and $27 \%$, respectively) of CD18.

\section{Discussion}

The $\beta_{2}$-integrin CD11b/CD18 is an integral membrane protein that is present in the plasma membrane and secondary granules of neutrophils and functions as a major adhesion molecule. Upon cellular activation, CD11b/CD18 is translocated from intracellular pools to the plasma membrane. This increased surface expression in concert with activation-induced avidity changes serves as a basis for enhanced cellular adhesion. Although the localization of CD11b/CD18 within neutrophils and its translocation following cell activation were well documented [24], mechanisms that govern the intracellular trafficking of CD11b/ CD18 are less well defined [25]. Patients with leucocytes exhibiting defects in the $\beta$-chain of CD11/CD18 suffer from severe bacterial infections [26] and the cells show various functional defects [23]. One may, therefore, expect that CD18 expression is linked to locomotor activity and that polarized cells show an increased expression of integrins. The integrin receptor complex functions as a transmembrane linkage connecting the cytoskeleton of the cell with extracellular matrix components [24]. Experiments in vitro suggested an association of integrins with cytoskeletal actin filaments going sequentially via $\alpha$-actinin, vinculin and talin to the integrin [25].

PMNs are important effector cells in host defense and inflammation. In recent years it has become increasingly evident that culturing PMNs in the presence of cytokines extends their life span [26]. Previous data by others suggested that PMNs express a receptor for IL-2. Interestingly, the present study confirms these data and provides evidence that PMNs express constitutively IL-2R in all observed cells. As previously shown for monocytes and NK cells [27], here we found only the IL-2Rb chain is expressed on PMNs, but not IL-Ra. This was confirmed by the flow cytometry results, where we detected only IL-2Rb chain on resting PMNs. This result encouraged our choosing of IL-2 as an activator of PMNs. IL-2 has a crucial role in several immunologic functions and its effect is dependent on the conjugation with IL-2R expressed on surface of activated cells and can release from them. Wang et al. found that there was a depression of IL-2R system in viral hepatitis B [28]. They concluded that these results 

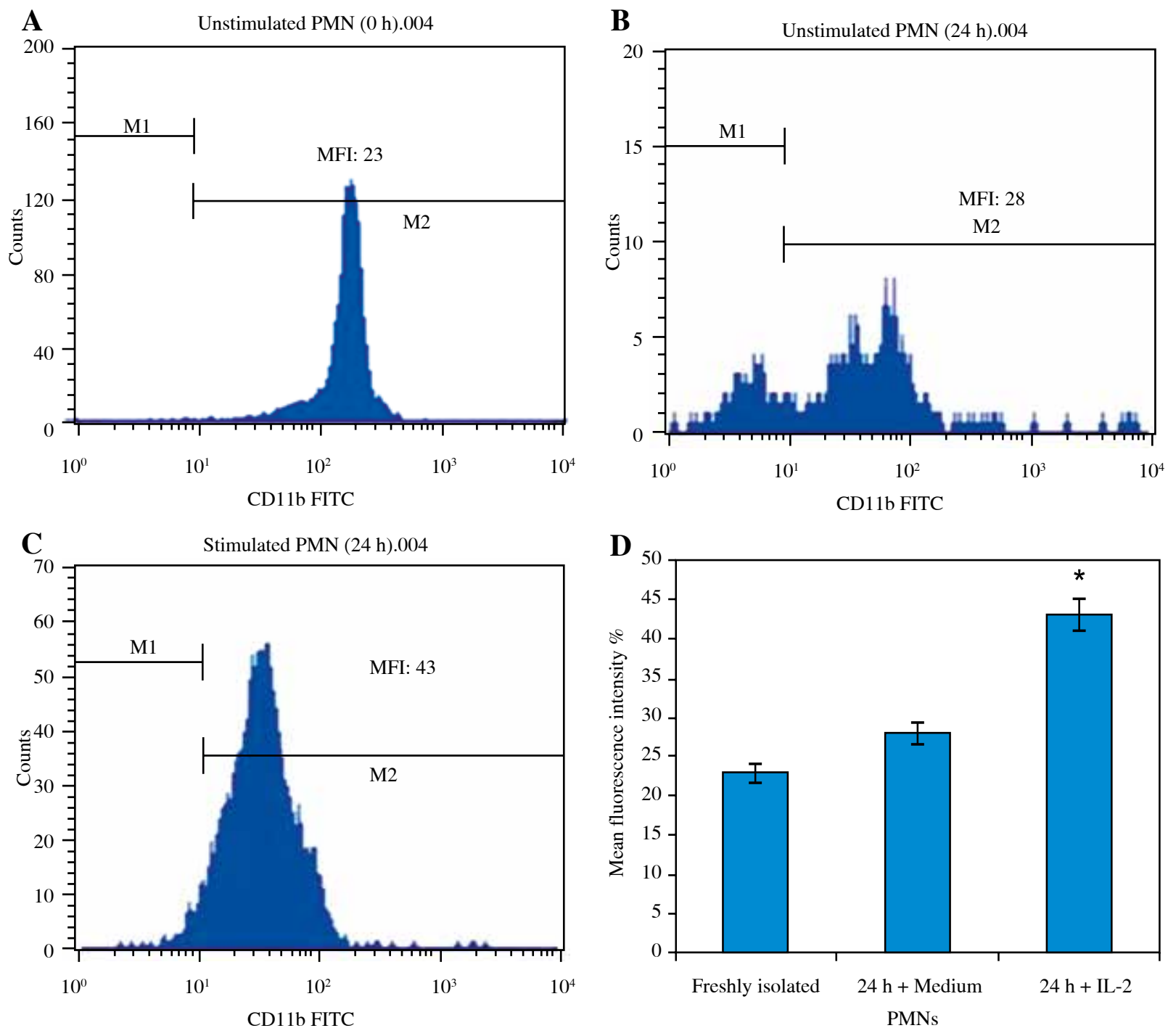

*shows the significance of IL-2 stimulated PMNs in comparison to the freshly isolated PMNs and PMNs cultured with medium alone for 24 hours

Fig. 3. Direct flow cytometry of the CD11 induction in highly purified PMN: A) Un-stimulated PMNs (0 hour). B) Un-stimulated PMNs (24 hours). C) Stimulated PMNs with IL-2 (24 hours). Values shown are mean values \pm SD

did no good to eliminate HBV and contribute to chronicity of hepatitis B. In this study, this means that the expression of IL-2R on the surface of PMNs has an important role to encourage the subsequent normal immune responses.

Furthermore, here we found that IL-2 has the capability to stimulate PMNs to express CD11b and CD18 which act as adhesion and migration molecules. CD11b is an immunological marker for early detection of neonatal sepsis [29] and a cell surface antigen of neutrophil [30]. Its expression on neutrophil cell surface, however, increases substantially within a few minutes after the cell comes into contact with bacteria or endotoxins [31]. This unique property enables $\mathrm{CD} 11 \mathrm{~b}$ to be used as a potential early warning marker for detection of bacterial infection. Engagement of CD11/ CD18 on mature neutrophils has been reported to induce either survival or apoptosis depending on the stimulus, the presence of cytokines, and other cues [32-36].

To the best of our knowledge, this study is the first to prove the up-regulation of CD11/CD18 on PMNs after stimulation with IL-2. This result indicates that IL-2 may have a crucial role in the PMNs migration. This study may provide critical insight for future strategies designed to enhance IL-2 against bacterial and viral infections. Furthermore, CD11/CD18 may be used as markers and could be potentially applied to identify life-threatening infection in preterm infants. 

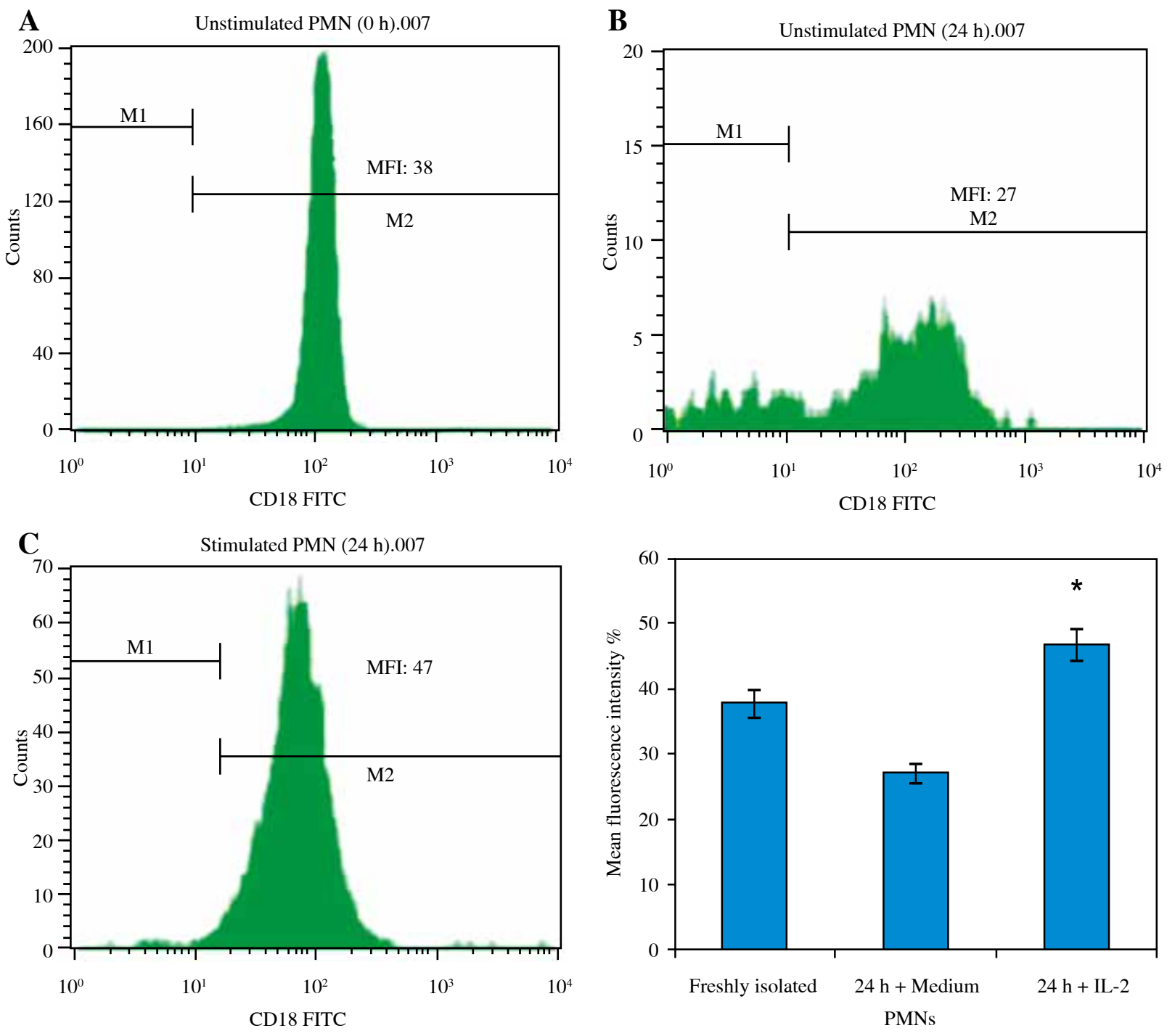

*shows the significance of IL-2 stimulated PMNs in comparison to the freshly isolated PMNs and PMNs cultured with medium alone for 24 hours

Fig. 4. Flow cytometry detection of CD18 in PMNs activated with IL-2 for 24 hours: A) Freshly isolated PMNs. B) Un-stimulated PMNs. C) IL-2 stimulated PMNs. Values shown are mean values \pm SD

The authors declare no conflict of interest.

This project was supported by King Saud University, Deanship of Scientific Research, College of Science Research Centre.

\section{References}

1. Rosales C, Juliano RL (1995): Signal transduction by cell adhesion receptors in leukocytes. Leukocyte Biol 57: 189-198.

2. Fina CB, Kazuaki M, Jennifer RA, et al. (2000): Integrin-mediated neutrophil adhesion and retinal leukostasis in diabetes. Invest Ophthalmol Vis Sci 41: 1153-1158.
3. Hynes RO (2002) Integrins: bidirectional, allosteric signaling machines. Cell 110: 673-687.

4. Danen EH, Sonnenberg A (2003): Integrins in regulation of tissue development and function. J Pathol 201: 632-641.

5. McIntyre TM, Prescott SM, Weyrich AS, Zimmerman GA (2003): Cell-cell interactions: leukocyte-endothelial interactions. Curr Opin Hematol 10: 150-158.

6. Feng D, Nagy JA, Pyne K, et al. (1998): Neutrophils emigrate from venules by a transendothelial cell pathway in response to fMLP. J Exp Med 187: 903-915.

7. Overbeek SA, Kleinjan M, Henricks PA, et al. (2013): Chemo-attractant $\mathrm{N}$-acetyl proline-glycine-proline induces CD11b/CD18-dependent neutrophil adhesion. Biochim Biophys Acta 1830: 2188-2193. 
8. Friedrichs K, Adam M, Remane L, et al. (2014): Induction of atrial fibrillation by neutrophils critically depends on $\mathrm{CD} 11 \mathrm{~b} /$ CD18 integrins. PLoS One 18: e89307.

9. Harris ES, McIntyre TM, Prescott SM, et al. (2000): The leukocyte integrins. J Biol Chem 275: 23409-23412.

10. Ebaid H. (2014): Neutrophil depletion in the early inflammatory phase delayed cutaneous wound healing in older rats: improvements due to the use of un-denatured camel whey protein. Diagn Pathol 4: 46.

11. Ebaid H, Ahmed OM, Mahmoud AM, et al. (2013): Limiting prolonged inflammation during proliferation and remodeling phases of wound healing in streptozotocin-induced diabetic rats supplemented with camel undenatured whey protein. BMC Immunol 25: 31.

12. Doerschuk CM, Winn RK, Coxson HO, et al. (1990): CD18-dependent and -independent mechanisms of neutrophil adherence in the pulmonary and systemic microvasculature of rabbits. J Immunol 114: 2327-2333.

13. Furie MB, Tancinco MCA, Smith CW (1991): Monoclonal antibodies to leukocyte integrins $\mathrm{CD} 11 \mathrm{a} / \mathrm{CD} 18$ and $\mathrm{CD} 11 \mathrm{~b} /$ CD18 or intercellular adhesion molecule-1 inhibit chemoattractant-stimulated neutrophil transendothelial migration in vitro. Blood 78: 2089-2087.

14. Mackay CR, Imhof BA (1993): Cell adhesion in the immune system. Immunol Today 14: 99-103.

15. Sampath R, Gallagher PJ, Pavalko FM (1998): Cytoskeletal interactions with the leukocyte integrin b2 cytoplasmic tail. J Biol Chem 273: 33588-33594.

16. Moulding, DA, Quayle JA, Hart CA, Edwards SW (1998): Mcl-1 expression in human neutrophils: regulation by cytokines and correlation with cell survival. Blood 92: 2495-2502.

17. Petroni KC, Shen L, Guyre PM (1988): Modulation of human polymorphonuclear leukocyte IgG Fc receptors and Fc receptor-mediated functions by IFN-g and glucocorticoids. J Immunol 140: 3467-3472.

18. Shen L, Guyre PM, Fanger MW (1987): Polymorphonuclear leukocyte function triggered through the high affinity $\mathrm{Fc}$ receptor for monomeric IgG. J Immunol 139: 534-538.

19. Lloyd AR, Oppenheim JJ (1992): Poly's lament: The neglected role of the polymorphonuclear neutrophil in the afferent limb of the immune response. Immunol Today 13: 169-172.

20. Espinoza-Delgado I, Ortaldo JR, Winkler-Pickett R, et al. (1990): Expression and role of p75 interleukin-2 receptor on human monocytes. J Exp Med 171: 1821-1826.

21. Waldmann TA (1989): The multi-subunit interleukin-2 receptor. Ann Rev Biochem 58: 875-911.

22. Djeu JY, Liu JH, Wei S, Rui H, et al. (1993): Function associated with IL-2 receptor b on human neutrophils: Mechanism of activation of antifungal activity against Candida alhicuns by IL-2. J Immunol 150: 960-970.

23. Degel J, Shokrani M (2010): Validation of the efficacy of a practical method for neutrophils isolation from peripheral blood. Clin Lab Sci 23: 94-98.

24. Repo H, Rochon YP, Schwartz BR, et al. (1997): Binding of human peripheral blood polymorphonuclear leukocytes to E-selectin (CD62E) does not promote their activation. J Immunol 159: 943-951.

25. Ke Z, Markus U, Yuan L, et al. (2004): Association of BAP31 with CD11b/CD18. J Biological Chemistry 279: 4492444930.

26. Larson RS, Springer TA (1990): Structure and function of leukocyte integrins. Immunol Rev 114: 181-217.
27. McEver RP (2002): Selectins: lectins that initiate cell adhesion under flow. Curr Opin Cell Biol 14: 581-586.

28. Horwitz A, Duggan K, Buck C, et al. (1986): Interaction of plasma membrane fibronectin receptor with talin - a transmembrane linkage. Nature 320: 531-532.

29. Burridge K, Fath K, Kelly T, et al. (1988): Focal adhesions: Transmembrane junctions between the extracellular matrix and the cytoskeleton. Annu Rev Cell Biol 4: 487-525.

30. Biffl WL, Moore EE, Moore FA, et al. (1996): Interleukin-6 delays neutrophil apoptosis. Arch Surg 131: 24-30.

31. Espinoza-Delgado I, Ortaldo JR, Winkler-Pickett R, et al. (1990): Expression and role of p75 interleukin-2 receptor on human monocytes. J Exp Med 171: 1821-1826.

32. Wang KX, Peng JL, Wang XF, et al. (2003): Detection of $\mathrm{T}$ lymphocyte subsets and mIL-2R on surface of PBMC in patients with hepatitis B. World J Gastroenterol 9: 2017-2020

33. Minoo A, Vajiheh O, Fakhri N, et al. (2007): Evaluation of $\mathrm{CD} 11 \mathrm{~b}$ expression on peripheral blood neutrophils for early detection of neonatal sepsis. Iran J Allergy Asthma Immunol 6: 93-96.

34. Lehr HA, Krombach F, Munzing S, et al. (1995): In vitro effects of oxidized low density lipoprotein on CD11b/CD18 and L-selectin presentation on neutrophils and monocytes with relevance for the in vivo situation. Am J Pathol 146: 218-227.

35. Mayadas TN, Cullere X (2005): Neutrophil beta2 integrins: moderators of life or death decisions. Trends Immunol 26: 388-395.

36. Savill J (1997): Apoptosis in resolution of inflammation. J Leukoc Biol 61: 375-380. 